\title{
Produção Fecal e Fluxo Duodenal de Matéria Seca e Matéria Orgânica Estimados por Meio de Indicadores ${ }^{1}$
}

\author{
Djalma de Freitas ${ }^{2}$, Telma Teresinha Berchielli ${ }^{3}$, Roselene Nunes da Silveira ${ }^{4}$, \\ João Paulo Guimarães Soares ${ }^{2}$, Juliano J. de Resende Fernandes ${ }^{5}$, Alexandre Vaz Pires ${ }^{6}$
}

RESUMO - O objetivo deste trabalho foi comparar os indicadores internos, fibra em detergente neutro e fibra em detergente ácido indigestíveis, obtidos após 144h de incubação in vitro e in situ (FDNiv; FDNis; FDAiv; FDAis) com o indicador externo, o óxido crômico $\left(\mathrm{Cr}_{2} \mathrm{O}_{3}\right)$, para estimativas da produção fecal, do fluxo duodenal de matéria seca e matéria orgânica em novilhos mestiços (HxZ) confinados. Foram utilizadas dietas à base de silagens de milho, de raspa e de casca de mandioca, e também de canade-açúcar ensilada com polpa cítrica peletizada. Os novilhos foram castrados e canulados no rúmen e no duodeno. O período experimental teve 11 dias de adaptação às dietas e 8 dias de coleta. O delineamento experimental foi o quadrado latino (4x4), com quatro tratamentos, num arranjo em parcela subdividida, sendo as dietas estudadas nas parcelas, e os indicadores nas subparcelas. Os resultados obtidos em percentagem do peso vivo para a estimativa da produção fecal, utilizando-se os diferentes indicadores, mostraram que a FDAiv $(0,88 \%)$, a FDAis $(0,85 \%)$ e o $\mathrm{Cr}_{2} \mathrm{O}_{3}(0,99 \%)$, embora com diferenças significativas, podem ser utilizados pelos resultados biologicamente consistentes. Para estimar o fluxo duodenal de matéria seca e matéria orgânica, foram utilizados os valores de produção fecal obtidos com a FDAiv. Os indicadores internos não apresentaram diferenças entre si para o fluxo duodenal de matéria seca, com média de $3,29 \mathrm{~kg}$ /dia, porém o óxido crômico superestimou o fluxo (4,95 kg/dia). Para o fluxo duodenal de matéria orgânica não houve diferença entre os indicadores com média de $2,73 \mathrm{~kg} / \mathrm{dia}$.

Palavras-chave: FDA indigestível, FDN indigestível, método in situ, método in vitro, óxido crômico

\section{Dry Matter and Organic Matter Fecal Output and Duodenal Flow Estimated by Markers}

\begin{abstract}
This research was conducted to compare the internal markers: indigestible neutral detergent fiber and acid detergent fiber, obtained after $144 \mathrm{~h}$ of in vitro (ivNDF, ivADF) and in situ (isNDF, is ADF) rumen incubations; and the chromium oxide $\left(\mathrm{Cr}_{2} \mathrm{O}_{3}\right.$ ) as external marker. The fecal output of dry matter and organic matter and the duodenal flow of crossbred steers, castrated and canulated in the rumen and in the duodenum. The steers were and fed with corn silage or the cassava hulls + citrus pulp, the cassava meal + citrus pulp, and sugar cane + citrus pulp, silages. The animals were adapted to diets during 11 days following 8 days for sampling. The dry matter and the organic matter duodenal flow estimated using the fecal output calculated by the ivADF. It was used a $4 \times 4$ Latin Square design with Split-splots. The fecal output results, expressed in live weight percentage, showed that the ivADF $(0.88 \%)$, is ADF $(0.85 \%)$ and $\mathrm{Cr}_{2} \mathrm{O}_{3}(0.99 \%)$ supplied biological consistent values and they could be used in spite of the significant differences among them. The internal markers did not show differences among them for the estimation of dry matter duodenal flow with an average of $3.29 \mathrm{~kg} / \mathrm{day}$. The chromium oxide overestimated the DM duodenal flow ( $4.95 \mathrm{~kg} /$ day). The organic matter duodenal flow estimates, there were no difference among the markers with an average of $2.73 \mathrm{~kg} /$ day.
\end{abstract}

Key Words: chromium oxide, indigestible ADF, indigestible NDF, in situ method, in vitro method

\section{Introdução}

A caracterização do valor nutritivo dos alimentos apresenta grande importância para os ruminantes, pois através dele pode-se inferir sobre a sua utilização por estes animais. O conceito de valor nutritivo envolve consumo, digestibilidade e eficiência de utilização do alimento.
Vários estudos têm sido realizados para medir a digestibilidade e associá-la às características bromatológicas dos alimentos, sendo essa estimada com relativa facilidade e eficácia (Mertens, 1994). A digestibilidade pode ser obtida pelo método direto, que implica em rigoroso controle de ingestão e excreção diário, o que pode torná-lo inviável em algumas situações (ensaios de pastejo) e também por

\footnotetext{
${ }^{1}$ Parte da dissertação de mestrado do primeiro autor.

${ }^{2}$ Aluno de Doutorado da FCAVJ/Unesp - Bolsista FAPESP. E.mail: djalma@fcav.unesp.br

${ }^{3}$ Professora do Depto. de Zootecnia da FCAVJ/UNESP.Pesquisadora do CNPq. E.mail: ttberchi@fcav.unesp.br

${ }^{4}$ Aluna de Doutorado da FCAVJ/UNESP - Bolsista CNPq.

${ }^{5}$ Aluno de Doutorado ESALQ/USP.

6 Professor do Depto de Zootecnia da ESALQ/USP
} 
ser um processo laborioso (Silva \& Leão, 1979). Alternativamente, tem sido proposto o método dos indicadores, ou indireto, que é fundamentado no emprego de uma substância índice ou indicador que, ao ser ingerida na dieta, deve ser totalmente recuperada nas fezes (Silva et al., 1968), permitindo assim estimar a produção fecal dos animais.

Várias metodologias utilizam indicadores inertes para se estimar a produção fecal. Essas determinações estão baseadas na razão entre a quantidade do indicador administrado ao animal e sua concentração nas fezes (Aroeira, 1997).

$\mathrm{O}$ método permite também a estimativa da digestibilidade de um alimento ou nutriente específico da dieta, assim como do fluxo duodenal de matéria seca, utilizando-se animais canulados no duodeno, que é a base para estudos de digestão parcial ao longo do trato digestório e do potencial de crescimento microbiano.

Os indicadores podem ou não estar presentes naturalmente na dieta, subdividindo-se em internos e externos. Entre os indicadores internos têm sido estudado alguns componentes da fração fibrosa dos alimentos, como a fibra em detergente neutro (FDNI) e da fibra em detergente ácido (FDAI), indigestíveis, lignina em detergente ácido (LDA), lignina em detergente ácido indigestível (LDAI), celulose potencialmente indigestível (CPI), cinza insolúvel em ácido (CIA) e cinza insolúvel em detergente ácido (CIDA). Estes indicadores podem ser utilizados tanto na estimativa da produção fecal como nas estimativas dos coeficientes de digestibilidade e ingestão de alimentos (Penning \& Johnson 1983a, b; Lippke et al., 1986; Resende et al., 1996; Ferret et al., 1999; Berchielli et al., 2000).

Os indicadores internos podem ser obtidos por incubações in situ ou in vitro. Piaggio et al. (1991) relataram problemas com o uso da FDA indigestível, obtida após incubação in situ, como indicador da digestibilidade. Esses autores relataram que a recuperação fecal e, conseqüentemente, a estimativa de digestibilidade foram abaixo do esperado. Contudo poderiam ser melhoradas com o uso da incubação in vitro, uma vez que essa apresenta menor variação e não apresenta perda de partículas.

Todavia, Resende et al. (1996) conduziram ensaio com cabritos que receberam dieta à base de milho desintegrado com palha e sabugo com suplementação concentrada e obtiveram resultados insatisfatórios. Esses autores iutilizarama FDAI (ob- tida in vitro) e a CIA para estimativa da digestibilidade da matéria seca, devido a sua baixa recuperação nas fezes, diferentemente do colágeno cromatado que não diferiu da coleta total.

Ferret et al. (1999) relataram recuperação fecal da FDAI não diferindo de $100 \%$, ao estudarem dietas à base de feno de Lolium multiflorum, suplementados ou não com $0,6 \mathrm{~kg}$ de concentrado por ovelha/dia, para os fenos de média e baixa qualidade. Contudo, para o feno de L. multiforum de alta qualidade, as recuperações foram inferiores, independente da suplementação $(88,1 \%$ e $83,1 \%)$, o mesmo ocorrendo para o feno de alfafa $(93,7 \%$ e $82,7 \%)$. Berchielli et al. (2000), ao compararem os indicadores FDAI, FDNI e lignina, incubados por 144 horas, na estimativa da digestibilidade não observaram diferença com os valores obtidos por coleta total de fezes, enquanto que, incubados por 72 horas, subestimaram os coeficientes de digestibilidade da matéria seca, proteína bruta, extrato etéreo, fibra em detergente neutro e energia bruta, assim como nutrientes digestíveis totais.

Dos indicadores externos o mais utilizado é o óxido crômico $\left(\mathrm{Cr}_{2} \mathrm{O}_{3}\right)$, sendo seu emprego bastante difundido para a estimativa da produção fecal, principalmente em ensaios de pastejo, pois permite estimar o consumo de forragem por meio da relação entre a produção fecal e a indigestibilidade da dieta (Astigarraga, 1997).

Detmann (1999), comparando três metodologias de fornecimento de cromo, por meio de infusão contínua, dosado em uma ou duas vezes ao dia e utilizando dosagem única com cromo mordante, na estimativa da produção fecal de bovinos em pastagem, suplementados ou não, observou, respectivamente, valores de 2,$82 ; 3,78$ e 3,56 para excreção fecal ( $\mathrm{kg} / \mathrm{dia}) ; 16,24 ; 10,29$ e 19,19 para coeficiente de variação e 0,$118 ; 0,100$ e 0,176 para erro padrão da média. Quando esses valores foram utilizados para estimativas do consumo dos animais, uma vez que não foi realizada a coleta total, inadequada a ensaios de pastejo, foi possível concluir que a metodologia de infusão contínua dosada uma vez ao dia forneceu o valor de excreção fecal mais consistente para a estimativa do consumo.

Em estudos conduzidos por Ferret et al. (1999) não foram observadas diferenças entre a coleta total de fezes e sua estimativa que foi calculada utilizandose o $\mathrm{Cr}_{2} \mathrm{O}_{3}$, uma vez que o mesmo apresentou valores de recuperação fecal que não diferiram de $100 \%$, 
exceto para o tratamento com feno de alfafa associado ao fornecimento de $0,6 \mathrm{~kg}$ de concentrado.

O óxido crômico também é utilizado para estimar fluxo de matéria seca e matéria orgânica no trato digestório, para posteriores inferências sobre o fluxo de proteína microbiana no duodeno, assim como sobre a partição da digestão dos nutrientes da dieta (Van Vuuren et al., 1999; Burger et al., 2000; Fregadolli, 2000).

Berchielli et al. (1998) compararam o óxido crômico e o cloreto de itérbio (indicadores externos) com a FDNI e a FDAI (indicadores internos) para estimativa do fluxo de matéria seca e matéria orgânica duodenal, em novilhos que receberam dietas com diferentes relações volumoso:concentrado. Concluíram então, que os indicadores internos podem ser utilizados para estimativa dos fluxos com alguma confiabilidade, o mesmo não ocorrendo para o $\mathrm{Cr}_{2} \mathrm{O}_{3}$ e o cloreto de itérbio que superestimaram os valores.

O objetivo do presente estudo foi comparar os indicadores internos, fibra em detergente neutro e fibra em detergente ácido, obtidos por meio de incubações in vitro (FDNiv e FDAiv) e in situ (FDNis e FDAis) por 144h, com o óxido crômico para estimativa da produção fecal e do fluxo duodenal de matéria seca e matéria orgânica em bovinos.

\section{Material e Métodos}

O experimento foi desenvolvido no Setor de Digestibilidade Animal do Departamento de Zootecnia da FCAV/UNESP, Campus de Jaboticabal, durante o período de julho a setembro de 1999.

Foram utilizados quatro novilhos mestiços (HxZ), fistulados e dotados de cânulas no rúmen e duodeno, castrados, com peso médio de 271,7 kg e 18 meses de idade, identificados com brincos. Durante o período pré-experimental, os animais foram desverminados e vacinados.

Os alimentos utilizados foram silagem de milho, casca de mandioca (constituída por cascas e pontas da mandioca residuais, obtidas após o processo de descascamento que ocorre durante a produção da farinha de mandioca), raspa de mandioca ( resíduo da fabricação do polvilho, que é obtido após lavagens consecutivas da massa de mandioca) e cana-deaçúcar.

A raspa e a casca de mandioca e a cana-deaçúcar foram ensiladas com polpa cítrica peletizada (PCP) em silos experimentais (manilhas de concreto com aproximadamente $3 \mathrm{~m}$ de altura por $1,5 \mathrm{~m}$ de diâmetro). As proporções de PCP utilizadas para raspa, casca e cana-de-açúcar foram de 46,6\%; 36,3 $\%$ e 44,6\%, respectivamente. O processo de ensilagem dos alimentos com a PCP teve por objetivo atingir teores de $40 \%, 35 \%$ e $40 \%$ de matéria seca, conforme o tratamento.

A partir da obtenção das silagens, que constituíram os tratamentos, foram formuladas quatro dietas, servindo uma serviu como dieta basal (silagem de milho + farelo de soja), ajustada conforme os princípios do AFRC (1995). Os tratamentos contendo as silagens de raspa e casca de mandioca com PCP, usadas como alimento energético, tiveram a dieta basal constituída de aproximadamente $60 \%$ da sua MS. O potencial de nitrogênio degradável foi ajustado por meio da uréia conforme o AFRC (1995), e o potencial de crescimento microbiano foi considerado como duas vezes a mantença.

A silagem de cana-de-açúcar com PCP teve apenas o potencial de nitrogênio degradável ajustado com uréia que foi fornecida exclusivamente. A composição química e percentual dos ingredientes nas rações (\%MS) encontram-se nas Tabelas 1 e 2.

As dietas foram fornecidas duas vezes ao dia, às 7 e 13 horas, juntamente com $70 \mathrm{~g}$ de mistura mineral/ animal/dia, sendo as sobras retiradas, pesadas e amostradas no dia seguinte. O consumo foi ajustado para manter as sobras em $10 \%$ da matéria seca oferecida.

As amostragens das silagens foram realizadas semanalmente e, ao final de cada período experimental, foram reunidas para formar uma amostra composta dentro do período.

O experimento teve duração total de 76 dias, divididos em 4 períodos de 19 dias, sendo 11 dias de adaptação à dieta e oito dias de coleta de amostras. Os animais foram mantidos em baias individuais durante 11 dias e a seguir, alojados em gaiolas para estudo de metabolismo, providas de bandeja coletora de fezes, com piso ripado de madeira e cochos apropriados para o fornecimento de alimento e água.

As coletas de fezes foram realizadas diariamente às 7 horas, sendo pesadas, homogeneizadas, amostradas, congeladas e, ao final de cada período, reunidas, para formar uma amostra composta por período e animal.

Concomitante à amostragem para a determinação da digestibilidade, foi realizada a coleta de conteúdo duodenal, via cânula, em quantidade de $500 \mathrm{~mL}$,

R. Bras. Zootec., v.31, n.3, p.1521-1530, 2002 (suplemento) 
Tabela 1 - Composição química e percentual dos ingredientes nas rações (\%MS)

Table 1 - Chemical and percent composition of ingredient in diets (\%DM)

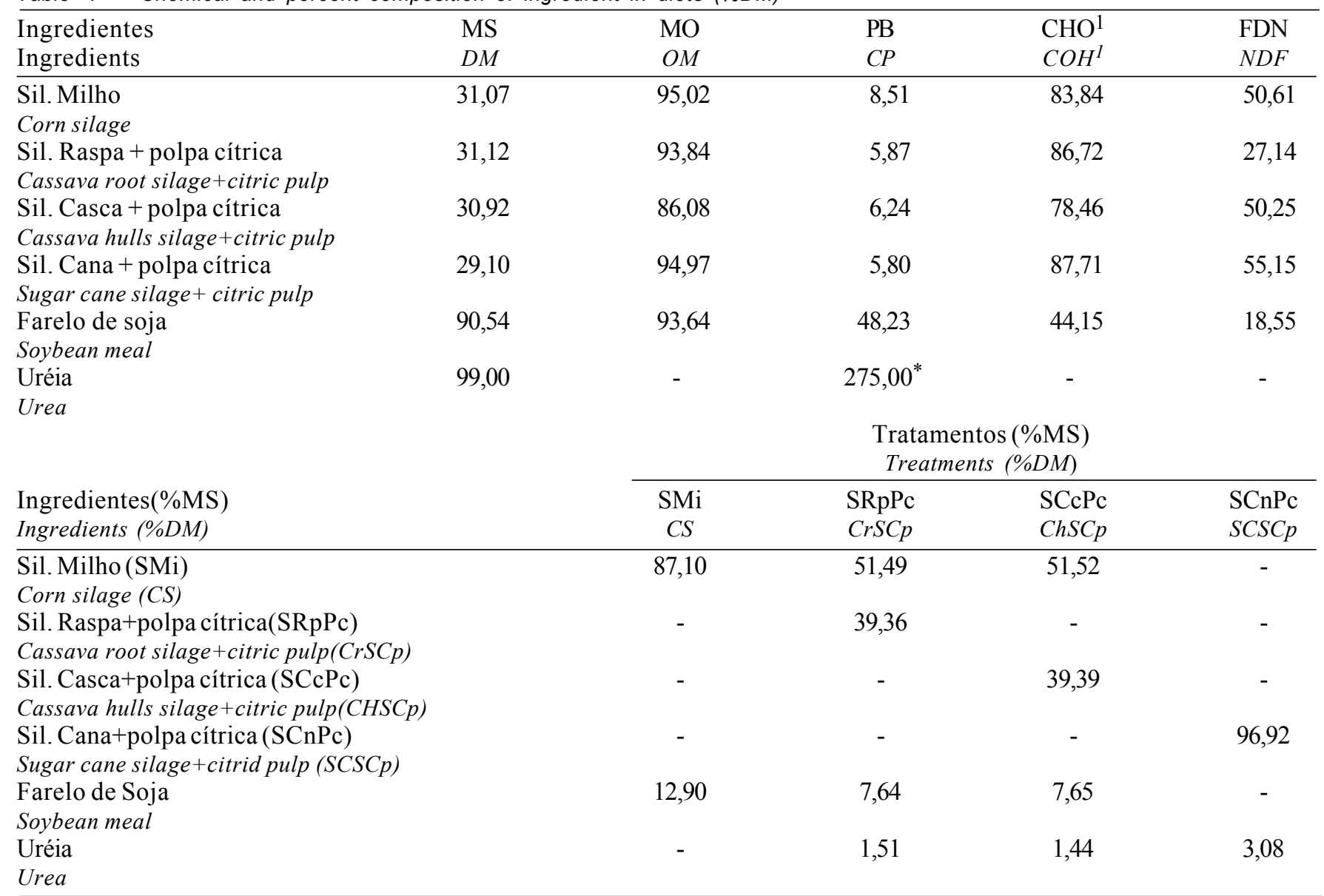

${ }^{*}=$ equivalente protéico.

${ }^{1} \mathrm{CHO}=100-(\% \mathrm{~PB}+\% \mathrm{EE}+\%$ cinzas $)$ Sniffen et al., 1992.

$\mathrm{MS}=$ matéria seca; $\mathrm{MO}=$ matéria orgânica; $\mathrm{PB}=$ proteína bruta; $\mathrm{CHO}=$ carboidratos totais; $\mathrm{FDN}=$ fibra detergente neutro

* $=$ protein equivalent.

${ }^{1} \mathrm{COH}=100-(\% \mathrm{CP}+\% \mathrm{EE}+\%$ ash $)$ Sniffen et al.,1992.

$D M=$ dry matter; $\mathrm{OM}=$ organic matter, $\mathrm{CP}=$ crude protein; $\mathrm{COH}=$ total carbohydrate; $N D F=$ neutral detergent fiber.

durante um período de quatro dias, conforme o esquema descrito a seguir: $1^{\circ} \mathrm{dia}-8 \mathrm{~h}$ e $16 \mathrm{~h} ; 2^{\circ} \mathrm{dia}-10 \mathrm{~h}$ e $18 \mathrm{~h} ; 3^{\circ}$ dia $-12 \mathrm{~h}$ e $20 \mathrm{~h}$ e $4^{\circ}$ dia às 14 horas. Após cada coleta, as amostras foram imediatamente congeladas para posterior determinação da $\mathrm{MS}$ a $65^{\circ} \mathrm{C}$ e, a seguir reunidas em uma amostra composta representando o respectivo tratamento e período.

A estimativa de produção fecal e fluxo duodenal de MS e MO foram calculadas com auxílio de quatro indicadores internos e um externo. Os indicadores internos utilizados foram a FDNiv e FDAis indigestíveis, obtidos após $144 \mathrm{~h}$ de incubação, sendo essa realizada in vitro e in situ (Berchielli et al., 1998 e Berchielli et al., 2000).

O indicador externo utilizado foi o óxido crômico, fornecido em duas doses diárias de 5 gramas, direta- mente no rúmen, via cânula. Sua administração iniciou-se 5 dias antes do período de coleta para que ocorresse o equilíbrio do indicador no trato gastrintestinal. O óxido crômico utilizado no experimento apresentou o teor de $63 \%$ de cromo, conforme análise laboratorial, segundo o método de Williams et al. (1962).

A produção fecal foi estimada, segundo Aroeira (1997), baseando-se na razão entre a quantidade do indicador administrado ao animal e sua concentração nas fezes, a partir da fórmula:

Produção fecal $(\mathrm{g} / \mathrm{dia})=$ Gramas de indicador ingerido

$$
\begin{aligned}
& \text { Concentração do } \\
& \text { indicador nas fezes }
\end{aligned}
$$

Para os cálculos de fluxo duodenal de MS foi utilizada a equação, em função do tipo de indicador 
Tabela 2 - Composição química dos tratamentos (\%MS)

Table 2 - Chemical composition of the treatments (\%DM)

\begin{tabular}{|c|c|c|c|c|c|c|}
\hline $\begin{array}{l}\text { Tratamentos } \\
\text { Treatments }\end{array}$ & $\begin{array}{l}\text { MS } \\
D M\end{array}$ & $\begin{array}{l}\mathrm{MO} \\
\mathrm{OM}\end{array}$ & $\begin{array}{l}\mathrm{PB} \\
C P\end{array}$ & $\begin{array}{l}\mathrm{CHO}^{1} \\
\mathrm{COH}^{1}\end{array}$ & $\begin{array}{l}\text { FDN } \\
N D F\end{array}$ & $\begin{array}{l}\mathrm{NDT}^{1} \\
T D N^{1}\end{array}$ \\
\hline $\begin{array}{l}\text { Silagem Milho } \\
\text { Corn silage }\end{array}$ & 38,83 & 94,90 & 13,63 & 78,71 & 46,48 & 57,73 \\
\hline $\begin{array}{l}\text { Sil. Raspa }+ \text { polpa cítrica } \\
\text { Cassava root silage }+ \text { citric pulp }\end{array}$ & 36,66 & 93,12 & 14,73 & 80,55 & 38,11 & 68,35 \\
\hline $\begin{array}{l}\text { Sil. Casca + polpa cítrica } \\
\text { Cassava hulls silage }+ \text { citric pulp }\end{array}$ & 36,49 & 90,02 & 14,28 & 77,62 & 47,33 & 50,05 \\
\hline $\begin{array}{l}\text { Sil. Cana + polpa cítrica } \\
\text { Sugar cane silage }+ \text { citric pulp }\end{array}$ & 31,25 & 92,16 & 13,78 & 85,14 & 53,51 & 59,83 \\
\hline
\end{tabular}

1 Valores calculados segundo Sniffen et al., 1992.

$\mathrm{MS}=$ matéria seca; $\mathrm{MO}=$ matéria orgânica; $\mathrm{PB}=$ proteína bruta; $\mathrm{CHO}=$ carboidratos totais; $\mathrm{FDN}=$ fibra detergente neutro; $N D T=$ nutrientes digestíveis totais.

1 Values calculated according to Sniffen et al.,1992.

$D M=$ dry matter; $O M=$ organic matter, $C P=$ crude protein; $C H O=$ total carbohydrates; $N D F=$ neutral detergent fiber; $T D N=$ total digestible nutrients.

(externo ou interno). Para o fluxo duodenal de MO utilizou-se o fluxo duodenal de MS multiplicado pelo teor de MO na amostra de digesta duodenal.

Indicador externo:

Fluxo Duodenal de MS = Gramas de indicador fornecido Concentração do indicador

(g)/g de MS duodenal

Indicador interno:

Fluxo de
Duodenal MS $=\frac{\begin{array}{l}\text { MS fecal } \\ \text { ou FDAiv (FDAis) na MS fecal }\end{array}}{\text { \% de FDNiv (FDNis) ou FDAiv }}$
(FDAis) indigestível na MS duodenal

em que: FDNiv = FDN obtida após incubação in vitro por 144h; FDNis = FDN obtida após incubação in situ por $144 \mathrm{~h} ;$ FDAiv = FDA obtida após incubação in vitro por 144h; FDAis = FDA obtida após incubação in situ por 144h; * = MS fecal estimada pela FDAiv.

As amostras de alimentos, sobras, fezes e conteúdo duodenal foram moídas e encaminhadas ao Laboratório de Nutrição Animal da FCAV/UNESP Campus de Jaboticabal, sendo então submetidas às análises de matéria seca (MS), matéria orgânica (MO), proteína bruta $(\mathrm{PB})$, extrato etéreo (EE), matéria mineral (MM), segundo procedimentos descritos pela AOAC (1990), e fibra em detergente neutro (FDN), segundo Jeraci et al., (1988).

O delineamento utilizado foi em quadrado latino $(4 \times 4)$, sendo o arranjo em parcela subdividida, as dietas estudadas nas parcelas, e os indicadores que estimaram produção fecal e o fluxo duodenal de MS e MO nas subparcelas. A análise de variância e a comparação de médias pelo teste de Tukey ao nível de $5 \%$ de probabilidade foram obtidas pelo PROC
GLM do Statistical Analisis Sistem (1985). Os valores obtidos foram analisados segundo o modelo:

$$
\mathrm{Y}_{\mathrm{ijkl}=\mu}+\mathrm{A}_{\mathrm{i}}+\mathrm{P}_{\mathrm{j}}+\mathrm{T}_{\mathrm{k}}+\mathrm{I}_{\mathrm{l}}+(\mathrm{AI})_{\mathrm{kl}}+(\mathrm{PI})_{\mathrm{jl}}+
$$

em que: $\mathrm{Y}_{\mathrm{ijkl}}=$ característica observada para a produção fecal e fluxo duodenal de MS e MO, para o iésimo animal, noj-ésimo período, k-ésimo tratamento; $\mu=$ média geral; $A_{i}=$ efeito do animal $\mathrm{i}(\mathrm{i}=1$ a 4 ); $\mathrm{P}_{\mathrm{j}}=$ efeito do período $\mathrm{j}(\mathrm{j}=1$ a 4$) ; \mathrm{T}_{\mathrm{k}}=$ efeito do tratamento $\mathrm{k}(\mathrm{k}=1$ a 4$) ; \mathrm{I}_{1}=$ efeito do indicador 1 $(1=1$ a 5$) ;(A I)_{i 1}=$ efeito da interação animal $x$ indicador; $(\mathrm{PI})_{\mathrm{j} 1}=$ efeito da interação período $\mathrm{x}$ indicador; $(\mathrm{TI})_{\mathrm{kl}}=$ efeito da interação tratamento $\mathrm{x}$ indicador; $\mathrm{e}_{\mathrm{ijkl}}=$ erro residual aleatório

\section{Resultados e Discussão}

A estimativa de produção fecal utilizando os indicadores está apresentada na Tabela 3. As interações entre indicador $\mathrm{x}$ animal, indicador $\mathrm{x}$ período e indicador $\mathrm{x}$ rações não foram significativas, $\mathrm{o}$ que indica uniformidade dos indicadores quanto àquelas possíveis fontes de variação, sendo então apresentadas as médias expressas em porcentagem do peso vivo $(\% \mathrm{PV})$ e $\mathrm{g} / \mathrm{kg} \mathrm{PV}{ }^{0,75}$, conforme o indicador utilizado.

Com a finalidade de verificar a adequação dos indicadores na estimativa da produção fecal, o consumo dos animais foi estimado considerando as digestibilidades médias obtidas e comparando-os com os determinados por meio das pesagens diárias do oferecido e das sobras (Freitas, 2002). Assim, para a estimativa da produção fecal, os valores obtidos com 
Tabela 3 - Valores estimados de produção fecal com o uso de indicadores internos, obtidos por duas metodologias in vitro e in situ após incubação por 144horas, e uso do $\mathrm{Cr}_{2} \mathrm{O}_{3}$, expressos em $\%$ do peso vivo e $\mathrm{g} / \mathrm{kg} \mathrm{PV}, 75$

Table 3 - Estimated values of feacal output by internal markers, obtained by in vitro and in situ methodologies after $144 \mathrm{~h}$ of incubation and $\mathrm{Cr}_{2} \mathrm{O}_{3}$ $\%$ of body weight and $\mathrm{g} / \mathrm{kg} \mathrm{BW} 0,75$

\begin{tabular}{lcc}
\hline $\begin{array}{l}\text { Métodos } \\
\text { Methods }\end{array}$ & \multicolumn{2}{c}{$\begin{array}{c}\text { Produção fecal } \\
\text { Feacal output }\end{array}$} \\
\cline { 2 - 3 } & $\begin{array}{c}\text { \% Peso Vivo } \\
\text { \%Body Weight }\end{array}$ & $\begin{array}{c}\mathrm{g} / \mathrm{kg} \mathrm{de} \mathrm{PV}^{0,75} \\
\mathrm{~g} / \mathrm{kg} \mathrm{BW}^{0.75}\end{array}$ \\
\hline FDNiv (NDF in vitro) & $0,74^{\mathrm{D}}$ & $29,96^{\mathrm{D}}$ \\
FDNis (NDF in situ) & $1,10^{\mathrm{A}}$ & $44,51^{\mathrm{A}}$ \\
FDAiv (ADF in vitro) & $0,88^{\mathrm{BC}}$ & $35,66^{\mathrm{BC}}$ \\
FDAis (ADF in situ) & $0,85^{\mathrm{CD}}$ & $34,19^{\mathrm{CD}}$ \\
$\mathrm{Cr}_{2} \mathrm{O}_{3}$ (chromic oxide) & $0,99^{\mathrm{AB}}$ & $40,24^{\mathrm{AB}}$ \\
DMS (MSD) & 0,13 & 5,38 \\
$\mathrm{CV}$ & 14,01 & 14,00
\end{tabular}

Médias seguidas por letras diferentes na coluna são diferentes pelo teste de Tukey $(P<0,05)$.

FDNiv - FDN obtido por incubação in vitro; FDNis - FDN obtido por incubação in situ.

FDAiv - FDA obtido por incubação in vitro; FDAis - FDA obtido por incubação in situ.

$\mathrm{Cr}_{2} \mathrm{O}_{3}$ - óxido crômico.

DMS - Diferença mínima significativa: CV - Coeficiente de Variação.

Means followed by different letters column are different by Tukey test $(P<.05)$.

NDFiv - NDF obtained by incubation in vitro; NDFis - NDF obtained by incubation in situ.

ADFiv - ADF obtained by incubation in vitro; ADFis - ADF obtained by incubation in situ.

$\mathrm{Cr}_{2} \mathrm{O}_{3}$ (chromic oxide).

MSD - Minimum difference significant; CV -Coefficient of Variation.

a FDAiv, FDAis e com o $\mathrm{Cr}_{2} \mathrm{O}_{3}$ apresentaram valores biologicamente adequados, o mesmo não ocorrendo com a FDNiv e FDNis, que subestimaram e superestimaram a produção fecal, respectivamente.

A estimativa de produção fecal obtida com a FDAiv foi a que permitiu maior aproximação entre os valores de consumo estimados e determinados (\% PV), 2,48 e 2,47 (Smi); 1,90 e 1,88 (SRp); 2, 11 e 2,13 $(\mathrm{SCc})$ e 1,40 e 1,39 (SCn), respectivamente, motivo pelo qual torna-se referência e permite a afirmativa de que a FDNiv e FDNis, subestimaram e superestimaram a produção fecal.

As produções fecais estimadas com óxido crômico apresentaram valores de 0,99 e 40,24, quando expressos em \% PV ou $\mathrm{g} / \mathrm{kg} \mathrm{PV}{ }^{0,75}$, respectivamente, não sendo verificada diferença significativa $(\mathrm{P}>0,05)$ em relação à fibra em detergente neutro in situ (FDNis) e fibra em detergente ácido in vitro (FDAiv), diferindo $(\mathrm{P}<0,05)$, entretanto, da fibra detergente ácido in situ (FDAis) e da fibra em detergente neutro in vitro (FDNiv), Esse último também não diferiu $(\mathrm{P}>0,05)$ da FDAis.

Os valores da estimativa da produção fecal obtidos pela FDNiv foram inferiores aos da FDNis, contrastando com o relatado por Piaggio et al., (1991) que, ao utilizarem a FDAI obtida por incubação in situ, durante dez dias, obtiveram recuperação fecal menor que $100 \%$. Esses autores atribuíram o resultado à perda de partículas pelos poros dos sacos de nylon, sugerindo que essa deficiência da metodologia poderia ser corrigida por meio da incubação in vitro.

No entanto essa incubação também apresenta como inconveniente o fato de partículas permanecerem aderidas à parede e à tampa do tubo, devido à agitação, ao invés de estarem em contato com o inóculo ruminal. Isso acarreta aumento do resíduo após incubação e superestima a quantidade do indicador presente na amostra. Para a estimativa com FDA os valores obtidos foram semelhantes $(\mathrm{P}>0,05)$, por ambas metodologias.

Rodriguez et al. (1994), ao compararem a produção fecal estimada, utilizando o cloreto de itérbio e o óxido crômico, com a obtida pela coleta total de fezes, observaram que os indicadores resultaram em valores semelhantes $(\mathrm{P}>0,05)$, quando expressos em $\mathrm{g} / \mathrm{kg}$ $\mathrm{PV}^{0,75}$. Contudo diferem da coleta total, apresentando valores de 41,$65 ; 40,60$ e 37,62, respectivamente $(\mathrm{P}<0,05)$.

Soares et al. (1999), trabalhando com vacas em lactação, que pastejavam capim-elefante associado com concentrado, obtiveram valores de $0,71 \% \mathrm{PV}$ e $33,88 \mathrm{~g} / \mathrm{kg} \mathrm{PV}^{0,75}$ para a excreção fecal estimada com o uso do cromo mordente. Esses valores foram inferiores aos obtidos neste estudo com o $\mathrm{Cr}_{2} \mathrm{O}_{3}$, porém próximos aos obtidos com o uso da FDAiv. Todavia Burger et al. (2000), utilizando bezerros holandeses e dieta com $45 \%$ de concentrado, obtiveram valores superiores, da ordem de $1,2 \% \mathrm{PV}$ e 41,02 $\mathrm{g} / \mathrm{kg} \mathrm{PV}{ }^{0,75}$, com alimentação ad libitum, sendo diferentes dos valores estimados pela maioria dos indicadores no presente estudo.

Os valores estimados de produção fecal, quando associados aos dados de digestibilidade para estimativa do consumo e sua comparação com o valor determinado por meio das pesagens diárias, permitem inferir que o indicador mais adequado foi a FDAiv. Os resultados acima concordam com os obtidos por Saliba et al. (1999), que compararam diversos indicadores internos e externos com o método de coleta 
total e observaram ser a FDAI a metodologia mais promissora, uma vez que os valores médios obtidos para digestibilidade da MS foram os mais próximos da coleta total. Em adição, Ítavo et al. (2000), ao utilizarem também a FDAI e FDNI, na estimativa de produção fecal e, posteriormente, ao analisarem os coeficientes de digestibilidade do feno de capim coast-cross, não observaram diferenças entre os indicadores, para a digestibilidade da MS (53,03 e $53,12 \%)$ e da PB $(46,30$ e $45,68 \%)$.

Os dados apresentados por Tibo et al. (2000) permitem observar valores médios de $0,63 \% \mathrm{PV}$ e $26,99 \mathrm{~g} / \mathrm{kg}$ $\mathrm{PV}^{0,75}$ para bovinos alimentados com $50 \%$ de concentrado. Da mesma forma, Dias et al. (2000) observaram valores médios de produção fecal da ordem de 0,69 $\% \mathrm{PV}$ e 27,82 g/ $\mathrm{kgPV}^{0,75}$ para bovinos alimentados com dietas à base de feno e concentrado (50:50). Esses valores estão abaixo dos verificados neste estudo, independentemente do indicador utilizado.

Os valores referentes às estimativas de fluxo duodenal de MS e de MO, foram calculados a partir da produção fecal estimada com a utilização do FDAiv, uma vez que esta apresentou valores biologicamente consistentes.

Na Tabela 4 encontram-se dispostos os dados referentes à estimativa do fluxo duodenal de MS, conforme a interação período $\mathrm{x}$ indicador que foi significativa $(\mathrm{P}<0,05)$.

Para o fluxo duodenal de MS, observa-se que a estimativa que utiliza o óxido crômico, no terceiro período, foi superior aos demais, sendo diferente também das estimativas com os indicadores internos, dentro do período $(\mathrm{P}<0,05)$. Isso se deve, possivelmente, ao fato de ter ocorrido uma baixa recuperação desse indicador na digesta duodenal, fato não esperado somente no $3^{\circ}$ período, uma vez que nos demais períodos o óxido crômico não diferiu $(\mathrm{P}>0,05)$ dos outros indicadores.

Tibo et al. (2000) observaram valores médios de fluxo duodenal de MS de 3,72 kg/dia, para bovinos alimentados com dietas contendo $50 \%$ de concentrado, sendo esse valor próximo ao verificado com os indicadores internos e inferior aos obtidos com óxido crômico.

Berchielli (1994) relatou a baixa recuperação do $\mathrm{Cr}_{2} \mathrm{O}_{3}$ no duodeno, subestimando a digestão ruminal da MS. O autor contrasta com Fregadolli et al. (2000) que observaram menor variação na estimativa do fluxo de MS obtida com o $\mathrm{Cr}_{2} \mathrm{O}_{3}$, quando comparada aos indicadores internos, CIA e FDNI, que apresen-

Tabela 4 - Fluxo duodenal de matéria seca, em $\mathrm{kg} / \mathrm{dia}$, estimada por meio de indicadores Table 4 - Duodenal flow of dry matter, kg/day, estimated by markers

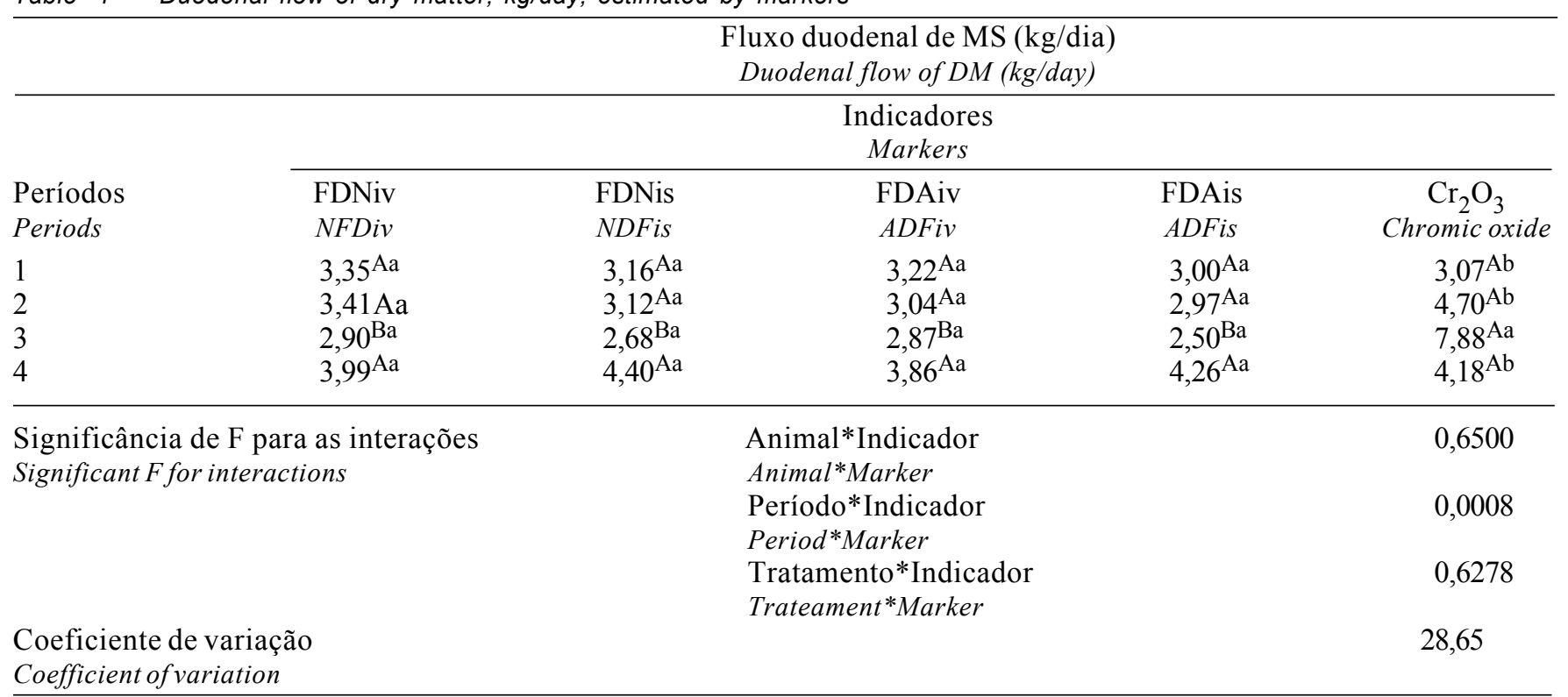

Médias Seguidas por letras diferentes, maiúscula na linha e minúscula na coluna são diferentes pelo teste de Tukey $(P<0,05)$. FDNiv - FDN obtido por incubação in vitro; FDNis - FDN obtido por incubação in situ.

FDAiv - FDA obtido por incubação in vitro; FDAis - FDA obtido por incubação in situ.

Average followed by different letters, majuscules row and minuscule column are different by Tukey test $(P<.05)$.

NDFiv - NDF obtained by incubation in vitro; NDFis - NDF obtained by incubation in situ.

ADFiv - ADF obtained by incubation in vitro; ADFis - ADF obtained by incubation in situ.

R. Bras. Zootec., v.31, n.3, p.1521-1530, 2002 (suplemento) 
taram maiores valores para o coeficiente de variação de $8,54 \% ; 10,62 \%$ e $22,12 \%$, respectivamente.

Os fluxos de MS estimados com o óxido crômico, freqüentemente observados na literatura, apresentam grande variação de resultados, como visto anteriormente. O cromo, contudo, é amplamente utilizado como indicador de fluxo da fase sólida ao longo do trato digestório (Valadares Filho et al., 1990; Elizalde et al., 1999; Van Vuuren et al., 1999).

Conforme os valores observados na Tabela 5, onde não foi considerada a interação período $\mathrm{x}$ indicador, verificou-se que o óxido crômico diferiu $(\mathrm{P}<0,05)$ de todos indicadores internos e esses não diferiram entre si $(\mathrm{P}>0,05)$ para o fluxo duodenal de MS. Isso possivelmente pode ser explicado em função dos indicadores internos estarem presentes no alimento e na digesta duodenal, em geral, de forma uniforme, permanecendo assim durante o processo de digestão e excreção ao longo do trato digestório (Berchielli et al., 1998). Contudo, para o fluxo duodenal de $\mathrm{MO}$, não foi verificada diferença $(\mathrm{P}>0,05)$ entre os indicadores, com média de $2,73 \mathrm{~kg} /$ dia.

Berchielli et al. (1998), ao trabalharem com o $\mathrm{Cr}_{2} \mathrm{O}_{3}$ e com o cloreto de itérbio, também observaram superestimativas do fluxo duodenal de $\mathrm{MS}$. $\mathrm{O} \mathrm{Cr}_{2} \mathrm{O}_{3}$ apresentou valores superiores para o fluxo estimado $(\mathrm{P}<0,05)$ em relação ao itérbio e ambos diferiram dos indicadores internos FDNI e FDAI. Esses autores concluíram que os indicadores internos podem ser utilizados como indicadores de fase sólida com alguma confiabilidade, resultados semelhantes aos observados no presente estudo (Tabela 5).

Os valores obtidos para o fluxo duodenal de MO (Tabela 6), apresentados conforme a interação entre período $\mathrm{x}$ indicador, mostram que as estimativas com o óxido crômico foram superiores $(\mathrm{P}<0,05)$ às obtidas com os indicadores internos no terceiro período. Houve, ainda, diferenças entre os períodos para a estimativa, quando se utilizou o $\mathrm{Cr}_{2} \mathrm{O}_{3}$. Tal fato pode estar associado ao teor de MO determinado na digesta duodenal que, no terceiro período, mostrou-se inferior aos demais.
Os coeficientes de variação observados para fluxo duodenal de MS e MO $(28,65$ e 29,76) foram superiores aos encontrados por Berchielli et al. (1998) $(14,8$ e 15,2) e Fregadolli et al. (2000), com valores de 8,54 e 22,12; e 9,89 e 26,92, respectivamente, para MS e MO, estimados com $\mathrm{Cr}_{2} \mathrm{O}_{3}$ e FDNI. Esse maior coeficiente de variação está associado à maior variabilidade dos valores estimados utilizando o $\mathrm{Cr}_{2} \mathrm{O}_{3}, \mathrm{o}$ que pode ter dificultado a obtenção de diferenças entre os indicadores.

Tabela 5 - Fluxo duodenal de matéria seca e de matéria orgânica estimada por meio de indicadores internos, obtidos in vitro e in situ, após incubação por 144 horas e do $\mathrm{Cr}_{\mathrm{s}} \mathrm{O}_{3}$, em kg/dia

Table 5 - Duodenal flow of dry matter and of organic matter estimated by internal markers, obtained by in vitro and in situ, after incubated 144 hours and $\mathrm{Cr}_{\mathrm{s}} \mathrm{O}_{3}, \mathrm{~kg} / \mathrm{day}$

\begin{tabular}{lcc}
\hline $\begin{array}{l}\text { Metodologias } \\
\text { Methodologies }\end{array}$ & \multicolumn{2}{c}{$\begin{array}{c}\text { Fluxo duodenal } \\
\text { Duodenal flow } \\
\text { kg/dia (kg/day) }\end{array}$} \\
\cline { 2 - 3 } & $\mathrm{MS}(D M)$ & $\mathrm{MO}(O M)$ \\
\hline FDNiv (NDF in vitro) & $3,41^{\mathrm{B}}$ & $2,69^{\mathrm{B}}$ \\
FDNis (NDF in situ) & $3,33^{\mathrm{B}}$ & $2,65^{\mathrm{B}}$ \\
FDAiv (ADF in vitro) & $3,24^{\mathrm{B}}$ & $2,56^{\mathrm{B}}$ \\
FDAis (ADF in situ) & $3,18^{\mathrm{B}}$ & $2,52^{\mathrm{B}}$ \\
$\mathrm{Cr}_{2} \mathrm{O}_{3}$ (chromic oxide) & $4,95^{\mathrm{B}}$ & $3,24^{\mathrm{B}}$ \\
\hline $\mathrm{DMS}$ (MSD) & 1,08 & 0,84 \\
$\mathrm{CV}$ & 28,65 & 29,76
\end{tabular}

Médias seguidas de letras diferentes, na coluna, são diferentes pelo teste de Tukey $(\mathrm{P}<0,05)$.

FDNiv - FDN obtido por incubação in vitro; FDNis - FDN obtido por incubação in situ.

FDAiv - FDA obtido por incubação in vitro; FDAis - FDA obtido por incubação in situ.

DMS - Diferença mínima significativa; CV - Coeficiente de variação.

Average followed by different letters, in the column, are different by Tukey test $(P<.05)$.

NDFiv - NDF obtained by incubation "in vitro; NDFis - NDF obtained by incubation "in situ".

ADFiv - ADF obtained by incubation "in vitro; ADFis - ADF obtained by incubation "in situ".

MSD - Minimum significant difference; CV - Coefficient of variation. 
Tabela 6 - Fluxo duodenal de matéria orgânica, em $\mathrm{kg} / \mathrm{dia}$, estimada por meio de indicadores Table 6 - Duodenal flow of organic matter, $\mathrm{kg} / \mathrm{day}$, estimated by markers

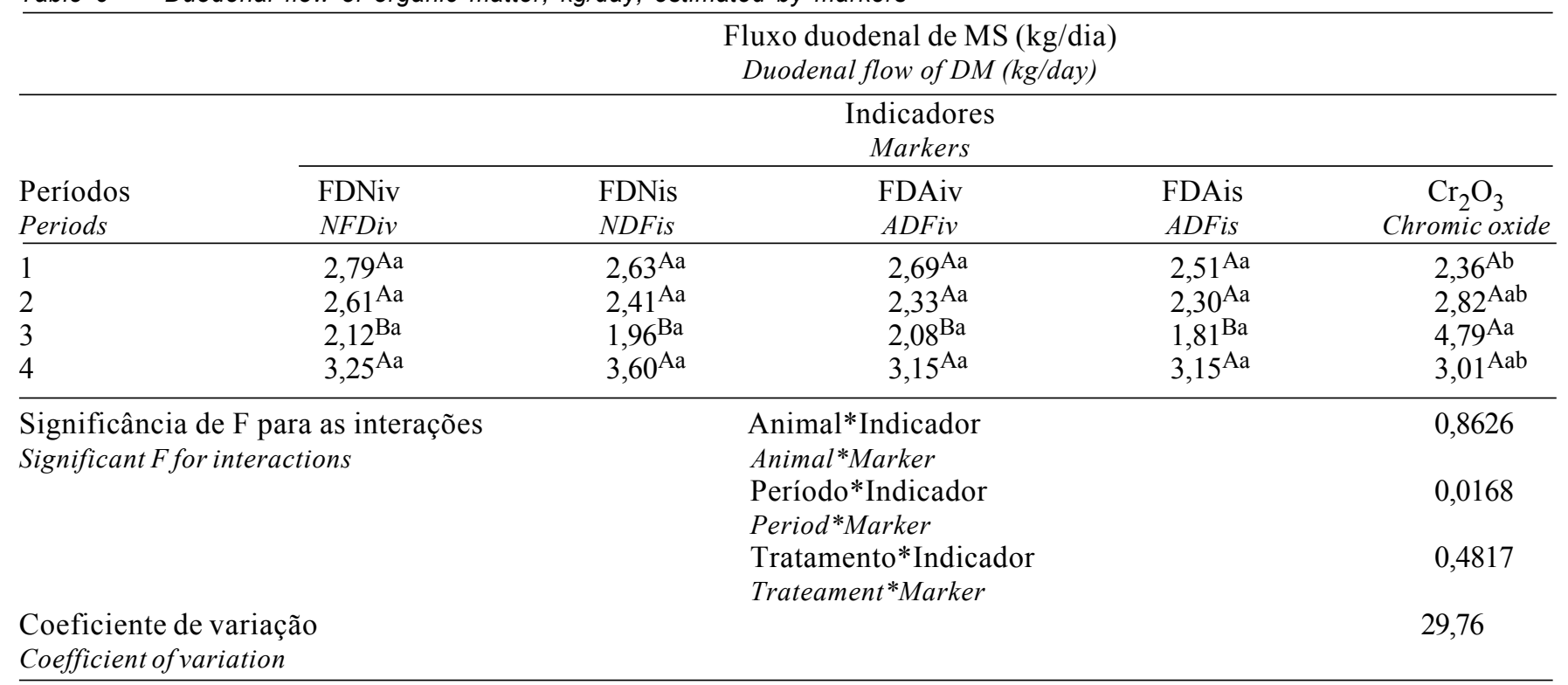

Médias seguidas por letras diferentes, maiúscula na linha e minúscula na coluna são diferentes pelo teste de Tukey $(P<0,05)$.

FDNiv - FDN obtido por incubação in vitro; FDNis - FDN obtido por incubação in situ.

FDAiv - FDA obtido por incubação in vitro; FDAis - FDA obtido por incubação in situ.

Average followed by different letters, maiúscula row and minúscula column are different by Tukey test $(P<.05)$.

NDFiv - NDF obtained by incubation in vitro; NDFis - NDF obtained by incubation in situ.

$A D F i v$ - ADF obtained by incubation in vitro; ADFis - ADF obtained by incubation in situ.

\section{Conclusões}

Dos indicadores estudados, FDAiv, FDAis e óxido crômico podem ser utilizados na estimativa da produção fecal. No entanto, como a técnica utilizada para obtenção da FDAiv é mais simples e econômica, dispensando também a utilização de animais fistulados, recomenda-se sua utilização como indicador em ensaios de digestibilidade.

Com a FDNiv e a FDNis subestimaram e superestimaram a produção fecal, a diferença entre eles pode estar associada a erros metodológicos, sendo necessárias mais pesquisas para que as duas metodologias sejam comparadas.

Para a estimativa do fluxo duodenal de MS e MO, os indicadores internos FDAiv, FDAis, FDNiv, FDNis mostraram-se adequados. Já o óxido crômico superestimou o fluxo de MS.

\section{Literatura Citada}

AGRICULTURAL AND FOOD RESEARCH COUNCIL AFRC. Technical committee on responses to nutrients: energy and protein requirements of ruminants. Wallingford: CAB International, 1995. 159p.

R. Bras. Zootec., v.31, n.3, p.1521-1530, 2002 (suplemento)
AROEIRA, L.J.M. Estimativas de consumo de gramíneas tropicais. In: SIMPÓSIO INTERNACIONAL DE DIGESTIBILIDADE EM RUMINANTES, 1997, Lavras, MG. Anais... Lavras: Universidade Federal de Lavras, 1997. p. 127-163.

ASSOCIATION OF OFICIAL ANALYTICAL CHEMISTIS AOAC. Official methods of analysis. Kenneth Helrich. 15.ed., Arlington, Virginia. 1990, v.2. 1298p.

ASTIGARRAGA, L. Técnicas para la medición del consumo de ruminantes en pastoreo. In: SIMPÓSIO SOBRE AVALIAÇÃO DE PASTAGENS COM ANIMAIS, 1997, Maringá. Anais... Maringá: Universidade Estadual de Maringá, 1997. p. 1-23.

BERCHIELLI, T.T., ANDRADE, P., FURLAN, C.L. Avaliação de indicadores internos em ensaios de digestibilidade. Revista Brasileira de Zootecnia, v.29, n.3, p.830-833, 2000.

BERCHIELLI, T.T.; RODRIGUEZ, N.M.; OSÓRIO NETO, E. et al. Comparação de indicadores de fase sólida para medir fluxo de matéria seca e matéria orgânica no duodeno. Arquivo Brasileiro de Veterinária e Zootecnia, v.50, n.2, p.147152, 1998.

BERCHIELLI, T.T. Efeito da relação volumoso:concentrado sobre a partição da digestão, a síntese de proteína microbiana, produção de ácidos graxos voláteis e o desempenho de novilhos em confinamento. Belo Horizonte: Universidade Federal de Minas Gerais, 1994. 104p. Tese (Doutorado em Zootecnia) - Universidade Federal de Minas Gerais, 1994.

BURGER, P.J.; PEREIRA, J.C.; SILVA, J.F.C. et al. Consumo e digestibilidade aparente total e parcial em bezerros holan- 
deses alimentados com dietas contendo diferentes níveis de concentrado. Revista Brasileira de Zootecnia, v.29, n.1, p.206-214, 2000.

DETMANN, E. Cromo e constituintes da forragem como indicadores, consumo e parâmetros ruminais em novilhos mestiços, suplementados durante o período das águas. Viçosa, MG: Universidade Federal de Viçosa, 1999. 103p. Dissertação (Mestrado em Zootecnia) - Universidade Federal de Viçosa, 1999.

DIAS, H.L.C.; VALADARES FILHO,S.C.; SILVA, J.F.C. et al. Consumo e digestões totais e parciais em novilhos $\mathrm{F} 1$ limousin $\mathrm{x}$ nelore alimentados com dietas contendo cinco níveis de concentrado. Revista Brasileira de Zootecnia, v.29, n.2, p.545-554, 2000.

ELIZALDE, J.C.; ALDRICH, C.G.; La COUNT, D.W. et al. Ruminal and total tract digestibilities in steers fed diets containing liquefied or prilled saturated fatty acids. Journal of Animal Science, v.77, n.2, p.1930-1939, 1999.

FERRET, A.; PLAIXATS, J.; CAJA, G. et al. Using markers to estimate dry matter digestibility, faecal output and dry matter intake in dairy ewes fed italian ryegrass hay or alfalfa hay. Small Ruminant Research, v.33, n. 2, p.145-152, 1999.

FREGADOLLI, F.L. Efeito das fontes de amido e nitrogênio de diferentes degradabilidades ruminais sobre o $\mathrm{pH}$ e Concentração de amônia no líquido ruminal e eficiência de síntese microbiana. Maringá: Universidade Estadual de Maringá, 2000. 69p. Dissertação (Mestrado em Zootecnia) - Universidade Estadual de Maringá, 2000.

FREGADOLLI, F.L.; ZEOULA, L.M.; KASSIES, M. et. al. Avaliação de indicadores no estudo da digestibilidade dos alimentos. In: REUNIÃO ANUAL DA SOCIEDADE BRASILEIRA DE ZOOTECNIA, 37., 2000, Viçosa. Anais... São Paulo: SBZ/Gmosis, [2000]. CD-ROM. Nutrição Ruminantes. Pôster-0556.

FREITAS, D.; BERCHIELLI, T.T.; SILVEIRA, R.N. Consumo e digestibilidade aparente total e parcial de rações com cana-de-açúcar e raspa de mandioca ensilados com polpa cítrica. R. Bras. Zootec., v.31, n.3, p.15311542, 2002. (suplemento)

ÍTAVO, L.C.V.; SILVA, F.F.; VALADARES FILHO, S.C. et al. Digestibilidade de fenos de gramíneas do gênero Cynodon através de indicadores internos. In: REUNIÃO ANUAL DA SOCIEDADE BRASILEIRA DE ZOOTECNIA, 37., 2000, Viçosa. Anais... São Paulo: SBZ/Gmosis, [2000]. CD-ROM. Nutrição Ruminantes. Pôster-1126.

JERACI, J.L.; HERNANDEZ, T.; ROBERTSON, J.B. et al. New and improved procedure for neutral detergent fiber. Journal of Animal Science, v.66, Suppl.1, p.351 (Abstracts), 1988.

LIPPKE, H.; ELLIS, W.C.; JACOBS, B.F. Recovery of indigestible fiber from feces of sheep and cattle on forage diets. Journal of Dairy Science, v.69, n.2, p.403-412, 1986.

MERTENS, D.R. Regulation of forage intake. In: FAHEY, G.C., COLLINS, M., MERTENS, D.R., MOSER, L.E. (Eds.). Forage quality, evaluation, and investigation. Madison: ASA, CSSA, SSSA, 1994. p.450-493.

PENNING, P.D.; JOHNSON, R.H. The use of internal markers to estimate herbage digestibility and intake. 1. Potentiality indigestible cellulose and acid insoluble ash. Journal Agricultural Science, v.100, n.1, p.127-131, 1983a.

PENNING, P.D.; JOHNSON, R.H. The use of internal markers to estimate herbage digestibility and intake. 2 . Indigestible acid detergent fiber. Journal Agricultural Science, v.100, n.1, p.133-138, 1983b.

PIAGGIO, L.M.; PRATES, E.R.; PIRES, F.F. et al. Avaliação das cinzas insolúveis em ácido, fibra detergente ácido indigestível e lignina em detergente ácido indigestível como indicadores internos da digestibilidade. Revista da Sociedade Brasileira de Zootecnia, v.20, n.3, p.306-312, 1991.

RESENDE, K.T.; FURLAN, C.L.; COSTA, R.G. et al. Utilização do colágeno cromatado como indicador em estudos de digestão com caprinos. Revista da Sociedade Brasileira de Zootecnia, v.25, n.4, p.807-813, 1996.

RODRIGUEZ, N.M.; BERCHIELLI, T.T.; OSÓRIO NETO, E. Uso de itérbio e cromo como indicadores fecais em bovinos. In: CONGRESSO BRASILEIRO DE MEDICINA VETERINÁRIA, 23., 1994, Olinda. Anais... Olinda, 1994. p.631.

SALIBA, E.O.S.; RODRIGUEZ, N.M.; GONÇALVES, L.C. et al. Estudo comparativo da lignina isolada da palha de milho, com outros indicadores em ensaio de digestibilidade aparente. In: REUNIÃO ANUAL DA SOCIEDADE BRASILEIRA DE ZOOTECNIA, 36., 1999, Porto Alegre. Anais... São Paulo: Gmosis, [1999] 293 pag. CD-ROM. Nutrição de Ruminantes. Digestibilidade e Degradabilidade in situ. NUR-129.

SANTOS, G.T.; PETIT, H.V. Prediction of fecal output in sheep fed silage using the captec chrome controlled-release capsule. Small Ruminant Research, v.20, n.2, p.223-227, 1996.

SAS INSTITUTE. Statistical Analysis System. User's Guide. 5.ed. Cary: 1985. 956p.

SILVA, J.F.C.; LEÃO, M.I. Fundamentos da nutrição dos ruminantes. Piracicaba, Livroceres. 1979. 380p.

SILVA, J.F.C.; CAMPOS, J.; CONRAD, J.H. Uso do óxido crômico na determinação da digestibilidade. Experientiae, v.8, n.1, p.1-23, 1968.

SNIFFEN, C.J.; O'CONNOR, P.J.; Van SOEST, P.J. et al. A net carbohydrate and protein system for evaluation cattle diets: II. Carbohydrate and protein availability. Journal Animal Science, v.70, n.3, p.3562-3577, 1992.

SOARES, J.P.G.; AROEIRA, L.J.M.; PEREIRA, O.G. et al. Capim-elefante (Pennisetum purpureum Schum.), sob duas doses de nitrogênio. Consumo e produção de leite. Revista Brasileira de Zootecnia, v.28, n.4, p.889-897, 1999.

TIBO, G.C.; VALADARES FILHO, S.C.; VALADARES, R.F.D. et al. Níveis de concentrado em dietas de novilhos mestiços F1 Simental x Nelore. 1 Consumo e digestibilidades. Revista Brasileira de Zootecnia, v.29, n.3, p.910-920, 2000.

VALADARES FILHO, S.C.; SILVA, J.F.C.; LEÃO, M.I. et al. Digestão total e parcial da matéria seca, matéria orgânica e carboidratos em novilhos holandeses, nelores e búfalos mestiços. Revista da Sociedade Brasileira de Zootecnia, v. 19, n.5, p.416-423, 1990.

Van VUUREN, A.M.; KLOP, A.; VAN DER KOELEN, C.J. et al. Starch and stage of maturity of grass silage: site of digestion and intestinal nutrient supply in dairy cows. Journal of Dairy Science, v.82, n.1, p.143-152, 1999.

WILLIAMS, C.H.; DAVID, D.J.; ISMAA, O. The determination of chromic oxide in faeces samples by atomic absorption spectophotometry. Journal of Animal Science, v.59, n.1, p.381-385, 1962 .

R. Bras. Zootec., v.31, n.3, p.1521-1530, 2002 (suplemento)

Recebido em: 27/08/01 Aceito em: 15/02/02 